\title{
Glutamate Acting on AMPA But Not NMDA Receptors Modulates the Migration of Hippocampal Interneurons
}

\author{
Jean-Bernard Manent, Isabel Jorquera, Yehezkel Ben-Ari, Laurent Aniksztejn, and Alfonso Represa \\ Institut de Neurobiologie de la Méditerranée, Institut National de la Santé et de la Recherche Médicale, Unité 29, 13273 Marseille, France
}

\begin{abstract}
Paracrine GABA and glutamate acting, respectively, on $\mathrm{GABA}_{\mathrm{A}}$ and NMDA receptors modulate the migration of hippocampal pyramidal cells. Using corticohippocampal organotypic explants from glutamic acid decarboxylase (GAD) 67- enhanced green fluorescent protein (EGFP) knock-in embryos, we now report that, in contrast to pyramidal neurons, the blockade of AMPA but not NMDA receptors exerts important actions on the migration of GABAergic interneurons. In addition, the blockade of $\mathrm{GABA}_{\mathrm{A}}$ receptors fails to modify the migration rates of GABAergic interneurons. Immunohistochemical analyses of GAD67-EGFP embryos (from embryonic day 14 to birth) reveal that interneurons colonize the hippocampal primordium by embryonic day 15 . At that stage, the hippocampal primordium is already composed of pioneer glutamatergic neurons, including (1) Cajal-Retzius cells, immunopositive to calretinin and reelin, and (2) other presumptive pioneer pyramidal cells that are immunopositive to $\beta$ III-tubulin and vesicular glutamate transporter 3 and immunonegative to GABA or GAD67. Therefore, the migrations of pyramidal neurons and GABAergic interneurons are cross-modulated: glutamate released from pioneer glutamatergic neurons facilitates the migration of GABAergic interneurons, which in turn would release GABA, facilitating the migration of glutamatergic neuroblasts. This general sequence may provide a retroactive positive loop needed to construct the hippocampal network. It might constitute a primitive homeostatic mechanism in the developing brain that acts to balance GABA-glutamate contributions to network construction and activity.
\end{abstract}

Key words: interneurons; migration; neurotransmitter; GABA; glutamate; AMPA; hippocampus

\section{Introduction}

Neuronal migration is a fundamental process of the CNS construction because neurons often migrate long distances from their birthplace to their final destination layers. The two major neuronal subtypes of the adult cortex, i.e., glutamatergic principal cells and GABAergic interneurons, are generated at distinct germinal zones and navigate along distinct migratory pathways (Nadarajah and Parnavelas, 2002; Marin and Rubenstein, 2003). Principal cells arise from the germinal zones lining the ventricle and migrate radially, following a relatively direct glial pathway to their destination layer into the developing cerebral cortex and hippocampus. Interneurons that are generated in the germinal zones of the basal ganglia primordium, i.e., the medial, lateral, and caudal ganglionic eminences, navigate tangentially into the developing cerebral cortex, covering long distances (for review, see Kriegstein and Noctor, 2004). The complex interneuronal migratory pathways within the neocortex have been investigated

\footnotetext{
Received Dec. 2, 2005; revised April 12, 2006; accepted April 16, 2006.

This work was supported by the Institut National de la Santé et de la Recherche Médicale, the Centre National de la Recherche Scientifique, the Conseil Régional Provence-Alpes-Côte-d'Azur, and the Fondation Française pour la Recherche sur l'Epilepsie. J.-B.M. received financial support from the Ministère de l'Education Nationale de la Recherche et de la Technologie and from the Ligue Française Contre I'Epilepsie. We are grateful to Drs. K. Obata and K. Vogt for kindly providing GAD67-EGFP knock-in mice and Drs. A. Goffinet, S. El Mestikawy, and G. Rougon for the generous gift of antibodies. We also thank T. Bourqua, C. Pellegrino, and E. Buhler for technical assistance.

Correspondence should be addressed to Alfonso Represa, Institut de Neurobiologie de la Méditerranée, Institut National de la Santé et de la Recherche Médicale, Unité 29, Campus de Luminy, Boite Postale 13, 13273 Marseille, France. E-mail: represa@inmed.univ-mrs.fr.

DOI:10.1523/JNEUROSCI.1033-06.2006

Copyright $\odot 2006$ Society for Neuroscience $\quad$ 0270-6474/06/265901-09\$15.00/0
}

using dye labeling (de Carlos et al., 1996; Lavdas et al., 1999; Jimenez et al., 2002; Ang et al., 2003), cultures of embryonic explants (Anderson et al., 1997, 2001; Polleux et al., 2002), grafting experiments (Wichterle et al., 2001; Nery et al., 2002), focal electroporation with fluorescent protein expression vector (Yozu et al., 2005), transgenic mice (Pleasure et al., 2000), or glutamic acid decarboxylase (GAD) 67-enhanced green fluorescent protein (EGFP) knock-in (KI) mice (Tamamaki et al., 2003; Tanaka et al., 2003). Recent studies revealed that migrating interneurons navigate along two main cortical streams: (1) subventricular zone (SVZ) and lower intermediate zone (IZ), and (2) marginal zone (MZ) and cortical subplate. They also migrate radially to reach their final destination layers [undergoing pial-oriented migration or ventricle-oriented migration (Nadarajah et al., 2002)] or obliquely between the main routes (Tanaka et al., 2003). However, the entry and migration pathways of interneurons within the hippocampus remain to be investigated.

Birthdating analyses (Stanfield and Cowan, 1979; Bayer, 1980; Soriano et al., 1989; Manent et al., 2005) indicate that both hippocampal neuronal subtypes, principal cells and interneurons, originate during a relatively large period of gestation [from embryonic day 12 (E12) to E18]. This implies that tangentially (ventrally originated) migrating cells encounter and assemble with radially migrating cells and pioneer neurons originated from the periventricular neuroepithelia. Both types of migration being essentially coexistent, it is likely that both cell types work together to form the proper time-dependent inside-out laminar gradients and yield to an equilibrated structure in terms of numbers of each 
respective cell type. One of the best illustrated communication between neurons relies on specific neurotransmitters (mainly GABA and glutamate) and receptors subtypes (mainly $\mathrm{GABA}_{\mathrm{A}}$ and NMDA receptors), which have been shown to modulate the migration of different neuronal subtypes, including, among others, cerebellar granule cells (Komuro and Rakic, 1993, 1998) and cortical (Behar et al., 1998, 1999, 2000; Hirai et al., 1999; Kihara et al., 2002) and hippocampal (Manent et al., 2005) pyramidal cell neuroblasts. These observations stress the notion that ambient GABA (normally released from migrating interneurons) might modulate the migration of glutamatergic neurons. Whether GABA and/or glutamate modulate the migration of interneurons remains unclear. Previous reports have suggested that migrating cortical interneurons express functional $\mathrm{GABA}_{\mathrm{A}}$ (Metin et al., 2000; Soria and Valdeolmillos, 2002), GABA $_{B}$ (Lopez-Bendito et al., 2003), and AMPA (Metin et al., 2000; Poluch et al., 2001; Soria and Valdeolmillos, 2002) receptors, but not NMDA receptors [(Metin et al., 2000) (but see Soria and Valdeolmillos, 2002)]. A blockade of $\mathrm{GABA}_{\mathrm{B}}$ receptors results in an accumulation of tangentially migrating neurons in the ventricular/subventricular zones of cortical explants, but the mechanisms of this action are presently not known (Lopez-Bendito et al., 2003). Interneuronal migration might also be modulated via AMPA receptor activation, as suggested by previous studies showing that migrating interneurons of the neocortical IZ express AMPA receptors (Metin et al., 2000) and that AMPA receptor activation affects the length of their processes (Poluch et al., 2001) as well as their GABA content (Poluch and Konig, 2002). However, the roles of $\mathrm{GABA}_{\mathrm{A}}, \mathrm{AMPA}$, and NMDA receptors on interneuronal migration have not been completely elucidated.

Using corticohippocampal explants from GAD67-EGFP knock-in embryos, we have now investigated whether GABA and glutamate modulate the migration of GABAergic interneurons. We report that AMPA receptor blockade prevents the migration of GAD67-EGFP interneurons, which fail to populate the hippocampal primordium. In contrast to pyramidal neuron migration, the blockade of neither $\mathrm{GABA}_{\mathrm{A}}$ nor NMDA receptors produces any significant effect on interneuronal migration. We conclude that different modes of migration (radial vs tangential) involving different cell types (principal pyramidal cells vs interneurons) are regulated throughout different mechanisms and suggest that glutamatergic and GABAergic neurons modulate their migration in a synergistic and cooperative manner.

\section{Materials and Methods}

Animals. Experiments were performed on E14-E17 mice embryos, from GAD67-EGFP knock-in mice, kindly provided by Dr. K. Obata (RIKEN Brain Science Institute, Wako, Japan) (Tamamaki et al., 2003). The GAD67-EGFP embryos were selected from the wild-type nonfluorescent littermates under a binocular microscope equipped with appropriate lamps and filters. All experimental procedures were performed in agreement with the European Union and French legislations concerning the animal care and use.

Pharmacological agents and antibodies. Pharmacological agents used in culture were as follows: 6-cyano-2,3-dihydroxy-7-nitroquinoxaline (CNQX), (5S,10R)-(+)-5-methyl-10,11-dihydro-5 $H$ dibenzo[a,d]cyclohepten-5,10-imine maleate (MK801), 2,3-dioxo6-nitro-1,2,3,4-tetrahydrobenzo[f]quinoxaline-7-sulfonamide (NBQX), 6-imino-3-(4-methoxyphenyl)-1(6H)-pyridazinebutanoic acid hydrobromide (gabazine), D-2-amino-5-phosphonovaleric acid (D-APV), and bicuculline (all obtained from Tocris Cookson, Bristol, UK).

Primary antibodies were as follows: mouse monoclonal, anti- $\beta$ IIItubulin (1:500; Sigma, St. Louis, MO), anti-GABA $\beta$ chain (1:200; Chemicon, Temecula, CA), anti-GAD67 (1:400; Chemicon), anti-GFP
(1:2000; Invitrogen, Carlsbad, CA), anti-nestin (1:1000; Becton Dickinson, Mountain View, CA), anti-reelin (G10, 1:1000; a generous gift from Dr. A. Goffinet, Université Catholique de Louvain, Brussels, Belgium), anti-vimentin (1:100; Sigma), anti-polysialic acid (PSA) (1:2; kindly provided by Dr. G. Rougon, Institut de Biologie du Développement de Marseille Luminy, Marseille, France); rabbit polyclonal, anti-calretinin (1: 2000; Swant, Bellinzona, Switzerland), anti-GABA (1:500; Sigma), antiGFAP (1:200; Sigma), anti-GFP (1:3000; Invitrogen), anti-AMPA/KA subunit 1 (GluR1) (1:600; Chemicon), anti-NR1 (1:200; Chemicon), anti-NR2A/B (1:400; Chemicon), anti-vesicular glutamate transporter 1 (vGlut1) (1:5000; SySy, Göttingen, Germany), anti-vGlut2, and antivGlut3 [both at 1:1000, a generous gift from Dr. S. El Mestikawy, Institut National de la Santé et de la Recherche Médicale, Unité 513, Creteil, France (Gras et al., 2005)]; guinea pig anti-doublecortin (1:2500; USBiological, Swampscott, MA); and rat anti-bromodeoxyuridine (BrdU) (1: 50; Harlan Sera-Lab, Loughborough, UK).

Secondary antibodies were as follows: donkey anti-mouse conjugated with FITC (1:200); goat anti-mouse conjugated with Texas Red (1:200); donkey anti-rat conjugated with FITC (Jackson ImmunoResearch, West Grove, PA); goat anti-rabbit or anti-guinea pig conjugated with cyanine 3 (1:200); and goat anti-rabbit conjugated with Alexa 488 (1:200) (Invitrogen).

Corticohippocampal organotypic slice culture. Pregnant animals were anesthetized with an intraperitoneal injection of chloral hydrate (7\%; Sigma) or killed by cerebral dislocation. Embryos were removed by cesarean section, and GAD67-EGFP embryos were selected as described above. Their brains were then removed and placed into Petri dishes containing cold PBS supplemented with glucose (30\%; Sigma) and penicillin-streptomycin (50 mg/ml; Invitrogen). After separation of the two hemispheres, they were cut into $350-400 \mu \mathrm{m}$ coronal slices using a tissue chopper (McIlwain; Campden Instruments, Leicester, UK), and slices were collected into $35 \mathrm{~mm}$ Petri dishes containing culture medium (MEM, 10\% horse serum, and $25 \mu \mathrm{g} / \mathrm{ml}$ insulin). Meninges were gently removed, and corticohippocampal slices were prepared under a dissecting microscope, with the help of microtweezers and spatula. Slices were cultivated onto the membrane of Millicell-CM inserts (Millipore, Bedford, MA), in six-well plates containing $1 \mathrm{ml}$ of culture medium per well, according to the protocol developed by Stoppini et al. (1991), adapted to embryonic tissues. Three corticohippocampal slices per inserts were arranged flat onto the membrane, and the excess of culture medium was removed. The six-well plates were kept for $3 \mathrm{~d}$ in vitro (DIV) at $37^{\circ} \mathrm{C}$ with $5 \% \mathrm{CO}_{2}$ and $95 \%$ air, in the presence/absence of pharmacological agents (see above). For cell proliferation and cell survival assay, culture medium was supplemented with $\mathrm{BrdU}$ (for $2 \mathrm{~h}$ before fixation of the slices, 50 $\mu \mathrm{g} / \mathrm{ml}$; Sigma) and propidium iodide ( $1 \mu \mathrm{l} / \mathrm{ml}$; Sigma), respectively (supplemental data, available at www.jneurosci.org as supplemental material).

Imaging of living slices was performed daily on a Nikon (Tokyo, Japan) Diaphot inverted microscope equipped with a Nikon DXM1200F digital camera and photomicrographs were digitized in .tiff format using the built-in software Nikon ACT-1. In addition, a few hippocampal slices (acute slices or cultured for $24 \mathrm{~h}$ ) were imaged on a Zeiss (Oberkochen, Germany) confocal microscope (LSM 510), using a $10 \times$ objective, for up to $140 \mathrm{~min}$. Images of the superficial migratory stream were taken every $10 \mathrm{~min}$, and stacks were reconstructed from 12 optical sections $(60.8 \mu \mathrm{m}$ thickness) using the built-in software LSM Image.

Immunohistochemistry on sections. Pregnant animals were anesthetized with an intraperitoneal injection of chloral hydrate (7\%; Sigma) or killed by cerebral dislocation. Briefly, embryos were removed by cesarean section, and GAD67-EGFP embryos were selected as described above. Their brains were then removed and maintained overnight into the fixative solution (4\% paraformaldehyde and $0.5 \%$ glutaraldehyde in PBS or $2 \%$ glutaraldehyde for GABA staining). After washes in PBS, brains were embedded in agarose and cut coronally with a vibratome (Leica, Nussloch, Germany). Sections were permeabilized for $10 \mathrm{~min}$ at room temperature in PBS-Triton X-100 (0.1\%)-goat serum (5\%). For BrdU staining, the permeabilization step was followed with a $20 \mathrm{~min}$ incubation in PBS- $2 \mathrm{~N} \mathrm{HCl}$ at $45^{\circ} \mathrm{C}$. After permeabilization, slices were washed three times in PBS and incubated overnight at room temperature with primary 
antibodies diluted in PBS-Triton X-100 (0.1\%)-goat serum (5\%). The slices were rinsed three times in PBS and were then incubated $2 \mathrm{~h}$ at room temperature in appropriated secondary antibodies, used separately for double immunolabelings. After three final washes in PBS, slices were mounted on glass slides and coverslipped in Gel Mount (Biomedia, Foster City, CA). Slices were examined on a Zeiss LSM 510 confocal microscope using $5 \times, 10 \times, 20 \times$, and $63 \times$ objectives, and photomicrographs were digitized using the built-in software LSM image.

Quantitative analysis of migrated cells. Photomontages were performed with Photoshop 7.0 (Adobe Systems, San Jose, CA). Corticohippocampal slices were reconstructed, the somata of migrated cells located into the hippocampal primordium were pointed by black dots, and quantitative analyses (cell densities) were performed using the analysis software NIH ImageJ 1.33d (Wayne Rasband, National Institutes of Health, Bethesda, $\mathrm{MD})$. All quantitative analyses were performed using stereological methods. The normality of the data distribution was checked using SigmaStat (Systat Software, Port Richmond, CA), and the statistical significance was assessed using appropriate tests.

\section{Results}

Tangentially migrating GAD67-EGFP interneurons populate the hippocampal primordium by E15, navigating along glutamate-enriched regions

Although the interneuronal migratory pathways within the neocortex have been well described (see Introduction), little is known concerning the migration of these neurons toward and within the hippocampal complex. To investigate this issue, we performed immunohistological analyses on sections from GAD67-EGFP KI embryos, from E14 to E17. At E14 (Fig. 1A), as described previously (Tanaka et al., 2003), migrating interneurons clearly formed two distinct migratory pathways within the cortical wall: one superficial, within the MZ and the cortical subplate, and the other, more important, in the lower IZ and SVZ. At that stage, we observed a few pioneer GAD67-EGFP interneurons migrating toward the hippocampal primordium. They navigated along a superficial migratory stream in the retrosplenial cortex and subicular area (Fig. 1A, 1). At E15 (Figs. 1B, 2C), migrating interneurons clearly populated the hippocampal primordium; they distributed within the subiculum and CA1 fields and coursed mainly a major migratory route in clear continuity with the cortical superficial stream. In contrast, the deeper cortical stream was interrupted at the junction between neocortex and subiculum (Figs. 1B, 2C). By E16 (Fig. 1C), interneurons colonizing the hippocampus via the superficial migratory stream now reached the CA3 field. However, the thinner deep migratory stream reached the CA1 field lining close to the ventricular zone but stopped by the border of CA3. Migrating interneurons reached the dentate gyrus primordium throughout the superficial migratory stream by E17 (data not shown). Quantitative analysis of cell densities evaluated in both the superficial and deep migratory streams clearly indicated that interneurons reach the hippocampus first through a superficial migratory stream and then through both superficial and deep migratory streams. The density of interneurons was higher in the superficial stream compared with the deeper stream (Fig. 1D). In conclusion, although interneurons migrate within the neocortex mainly along a deeper pathway following the subventricular zone and the lower intermediate zone, they invade the hippocampus throughout a mainly superficial path below the marginal zone.

To confirm that GAD67-EGFP-positive cells represent tangentially migrating neurons, double immunostainings were performed with specific antibodies of radial glia (nestin) and migrating neurons (doublecortin and PSA). At any embryonic stage analyzed, GAD67-EGFP cells displayed the typical morphology of migrating neurons (small round-shaped cell body, branched
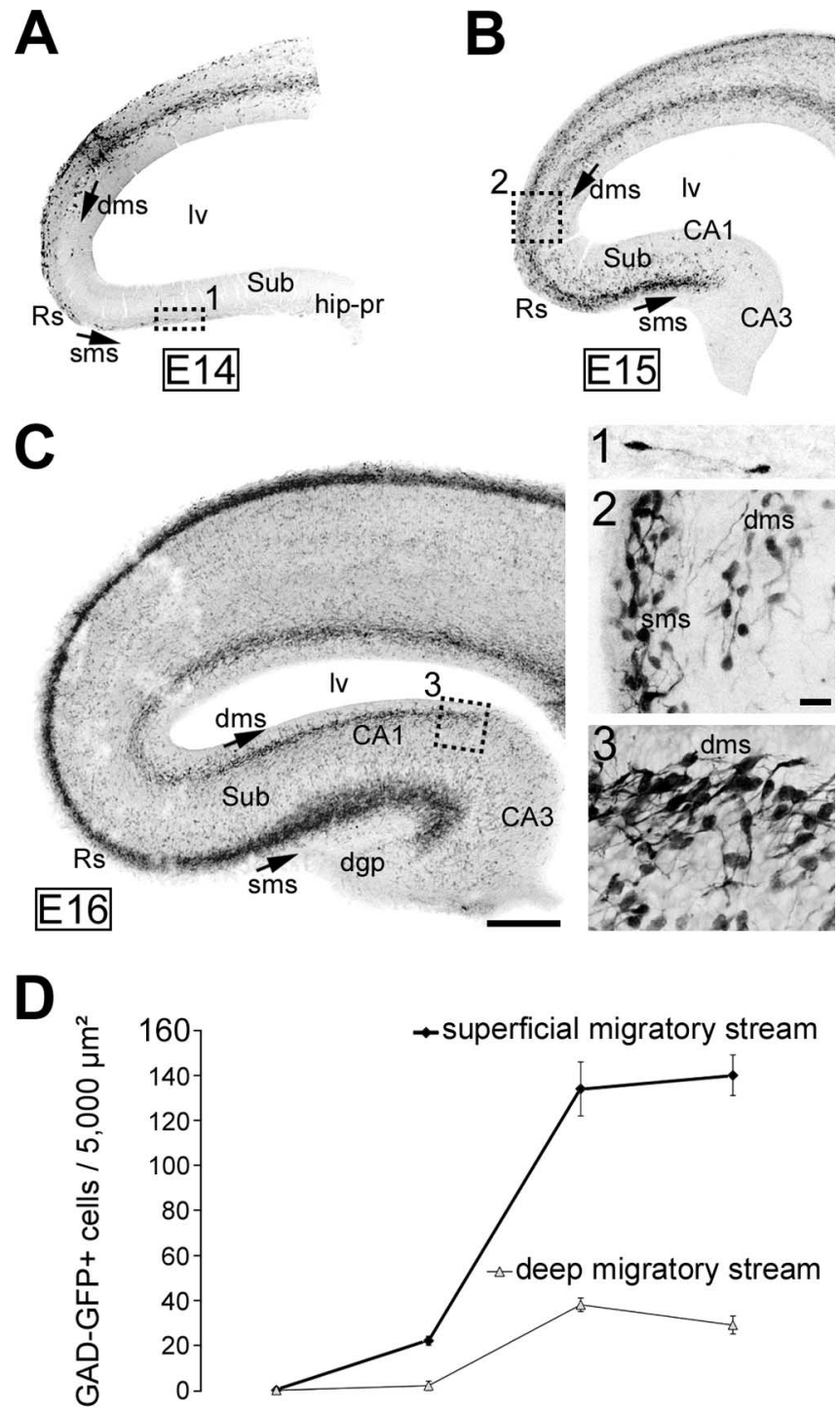

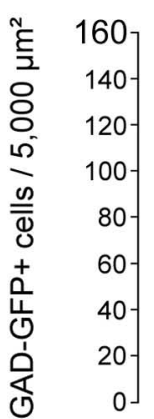

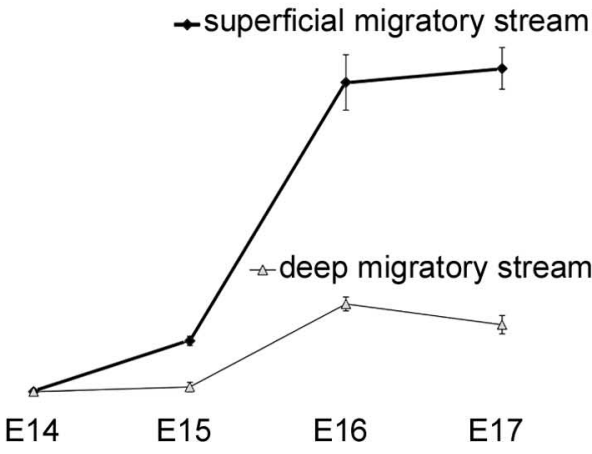

Figure 1. Interneuronal migratory pathways: toward and within the hippocampal primordium in GAD67-EGFP KI mice. $\boldsymbol{A}$-C, Confocal photomicrographs of E14 (A), E15 (B), and E16 (C) coronal sections from GAD67-EGFP embryos, stained with antibodies against GFP (in black). Squares were enlarged in 1-3, respectively. GAD67-EGFP interneurons migrating tangentially within the neocortical wall navigate along two major migratory routes at E14: (1) a superficial migratory stream, lining the cortical marginal zone; and (2) a deep migratory stream, following the cortical subventricular zone and lower marginal zone. $A$, Pioneer interneurons migrating to the hippocampal primordium (square shown enlarged in 1) follow the superficial migratory stream. $\boldsymbol{B}$, Migrating interneurons reach the $\mathrm{CA} 1$ field at $\mathrm{E} 15$ exclusively through the superficial migratory stream; the deep migratory stream stops at this age by the border of the subicular area (enlarged in 2). C, Migratory interneurons reach the CA3 field at E16 again through the superficial stream; the dentate gyrus is not yet colonized. The deep migratory stream stops at this age by the border of CA2-CA3 (enlarged in 3). dgp, Dentate gyrus primordium; dms, deep migratory stream; hip-pr, hippocampal primordium; Iv, lateral ventricle; $\mathrm{Rs}$, retrosplenial cortex; sms, superficial migratory stream; Sub, subiculum. Scale bars: $A-C, 100 \mu \mathrm{m} ; 1-3,20 \mu \mathrm{m}$. D, Quantitative analysis of GAD67-EGFP-positive cell densities in the superficial and deep migratory streams in the hippocampal primordium as a function of age. Analyses were performed at the front of the migratory streams, in three different sections from the dorsal hippocampus from E14-E17 GAD67-EGFP KI embryos ( $n=3$ hippocampi per age). Note that the cellular density is higher in the superficial migratory stream and that cells traveling through the deep migratory stream reach the hippocampal primordium later than those of the superficial stream. 
leading process) and were clearly immunopositive to both doublecortin (Fig. $2 \mathrm{~A}$ ) and PSA (Fig. $2 B$ ). These cells ran below the marginal zone crossing nestin-positive extensions (radial glial extensions) (Fig. $2 C)$, the majority of leading process being oriented perpendicularly to radial glial extensions. In addition, few GAD67-EGFP cells could be observed to emerge from the superficial migratory stream and to follow radial glial extensions (Fig. $2 C$ ), suggesting that, in the hippocampus as in the neocortex, GABAergic neurons change their migration mode from tangential to radial to colonize the hippocampal plate. To further stress the migrating activity of GAD67-EGFP cells in the hippocampal primordium, time-lapse analyses were performed on acute or cultured E15 slices (Fig. 2D). Experiments were repeated five times. Slices were recorded for up to 140 min using a confocal microscope. Leading processes displayed a quite dynamic behavior, with growth cones motility, extensions, and retractions. Rapid extensions of leading processes were followed by somal translocations. These observations strongly indicate that hippocampal GAD67-EGFP cells in the superficial migratory stream are tangentially migrating neurons.

To elucidate the cellular composition of the interneuronal migratory pathways within the hippocampal primordium, counterstainings with a Nissl dye (Neurotrace) or immunostainings with specific markers of Cajal-Retzius cells (reelin and calretinin), glutamatergic neurons (vGlut1, vGlut2, and vGlut3), and interneurons (GABA and GAD67) were performed on E15 slices from GAD67-EGFP KI embryos. Nissl stainings (Fig. $3 A-C$ ) revealed that the GAD67-EGFP interneurons of the hippocampal superficial migratory stream travel at the junction between the marginal zone and the hippocampal plate in the subicular area (Fig. $3 B$ ) and clearly invade the hippocampal plate in the CA1 field (Fig. 3C). Cells located into the marginal zone were, as expected, immunopositive for calretinin (Fig. $3 D, E$ ) and reelin (Fig. $3 J, K$ ), two specific markers of the Cajal-Retzius cells. Tangentially migrating interneurons were observed to navigate below this layer of Cajal-Retzius cells, never invading the marginal zone. Furthermore, tangentially migrating interneurons were never found immunopositive for reelin or calretinin (Fig. $3 E, K$ ). We then analyzed the cellular composition of the hippocampal primordium. When the pioneer GAD67-EGFP interneurons invaded the hippocampal
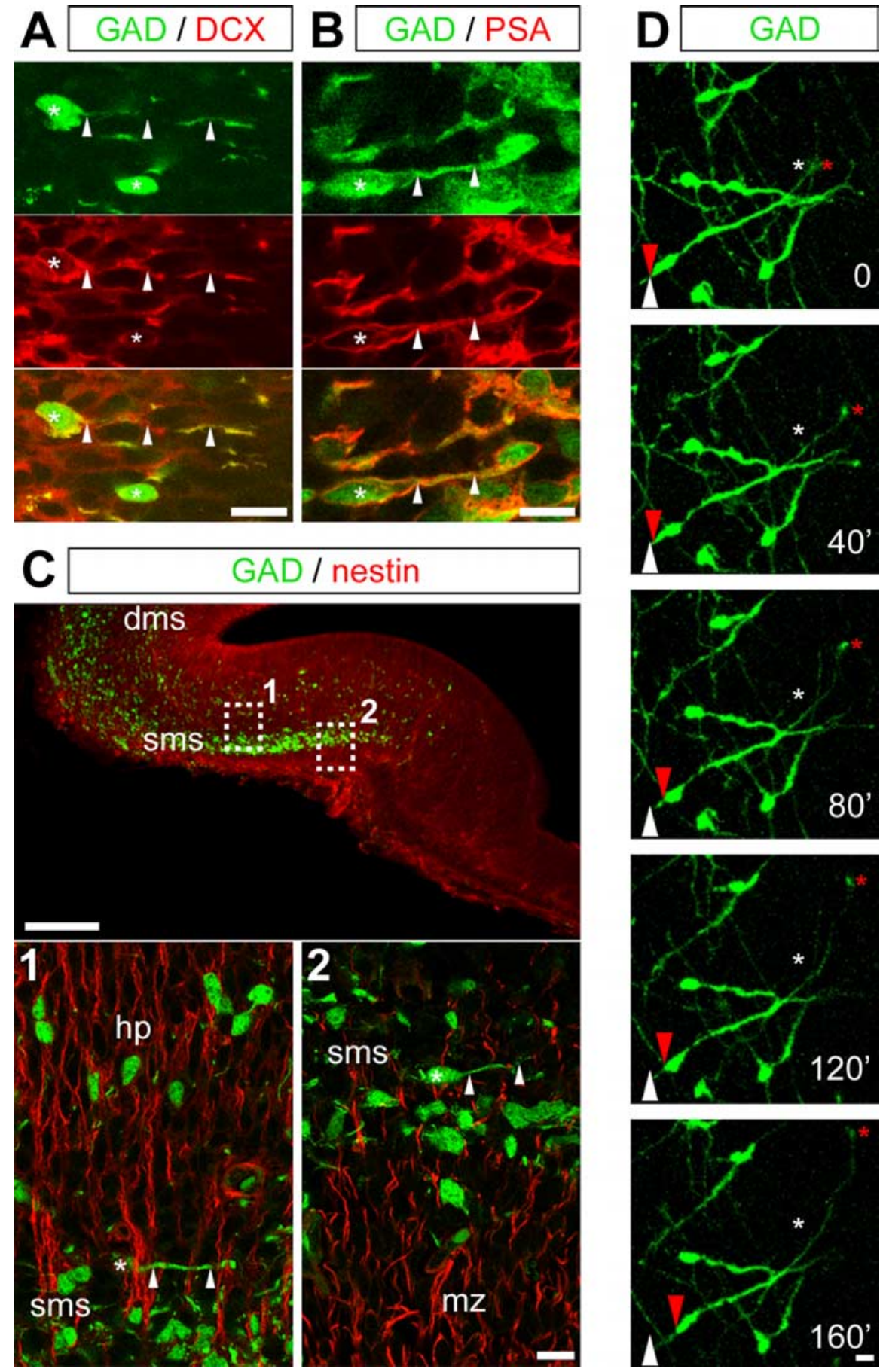

Figure 2. GAD67-EGFP cells are tangentially migrating neurons. $\boldsymbol{A}, \boldsymbol{B}$, Confocal photomicrographs (z-projections) of E15 coronal hippocampal sections double labeled with antibodies against GFP (green) and doublecortin (DCX;A) and PSA (B) (red), two markers of immature migrating neurons. Merged images are shown in the bottom panels. Cell bodies are indicated by asterisks, and processes are indicated by arrowheads. C, Confocal photomicrographs (z-projections) of E15 coronal hippocampal sections double labeled with antibodies against GFP (green) and nestin (red), which here stains radial glia. Squares 1 and 2 were enlarged in the bottom panels. In the superficial migratory stream, GAD67-EGFP-positive neurons display the typical morphology of migrating neuroblasts, with a leading process arranged tangentially to the orientation of radial glial processes. In the hippocampal plate, GAD67-EGFP-positive neurons appear in contrast to follow radial glial extensions, thus suggesting that, in the hippocampal complex, interneurons change their mode of migration from tangential to radial, to colonize deeper hippocampal layers. $\boldsymbol{D}$, Time-lapse analysis of an E15 coronal hippocampal section from GAD67-EGFP KI mice. This section was incubated for 1 DIV before analysis as indicated in Material and Methods. Each time point (every $40 \mathrm{~min}$ ) corresponds to a z-projection of 12 focal planes (60.8 $\mu \mathrm{m}$ thickness). Red arrows and asterisks point to moving cell bodies and terminal tips, respectively. White arrows and asterisks point to the initial position of these elements. dms, Deep migratory stream; hp, hippocampal plate; $\mathrm{mz}$, marginal zone; sms, superficial migratory stream. Scale bars: $A, B$, bottom in $C, D, 10 \mu \mathrm{m}$; top in $C, 100 \mu \mathrm{m}$. 

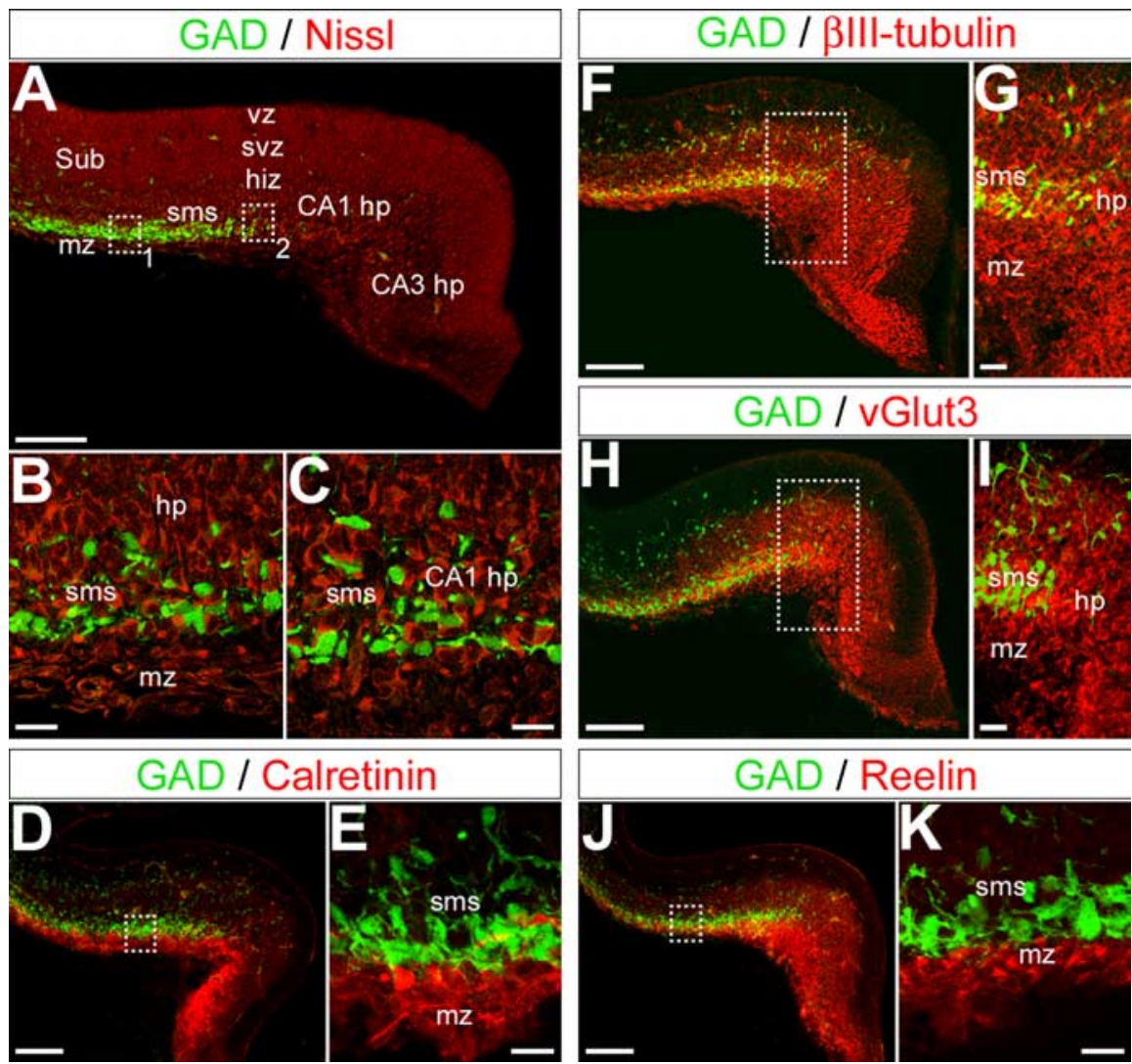

Figure 3. GAD67-EGFP interneurons navigate within the hippocampal primordium, which is composed of pioneer glutamatergic neurons. $\boldsymbol{A}-\boldsymbol{C}$, Confocal photomicrographs (single optical sections) of an E15 coronal hippocampal section immunostained for GFP (green) and Nissl counterstain (Neurotrace, deep red). Squares labeled 1 and 2 in $\boldsymbol{A}$ are enlarged in $\boldsymbol{B}$ and $\boldsymbol{C}$, respectively. GAD67-EGFP interneurons form a band of migrating cells below the marginal zone and intermingle with "neuronal" cells contributing to form the hippocampal plate in the subiculum $(\boldsymbol{B})$ and the hippocampal primordium (C). $\boldsymbol{D}-\boldsymbol{K}$, Confocal photomicrographs (z-projections) of E15 coronal hippocampal sections double labeled with antibodies against GFP (green) and antibodies to calretinin $(\boldsymbol{D}, \boldsymbol{E}), \beta \| I I$-tubulin $(\boldsymbol{F}, \boldsymbol{G}), \mathrm{vGlut} 3(\boldsymbol{H}, \boldsymbol{I})$, and reelin $(\boldsymbol{J}, \boldsymbol{K})($ red). Squares in $\boldsymbol{D}, \boldsymbol{F}, \boldsymbol{H}$, and $\boldsymbol{J}$ are enlarged in $\boldsymbol{E}, \boldsymbol{G}, \boldsymbol{I}$, and $\boldsymbol{K}$, respectively. Note that the superficial migratory stream forms a band adjacent to the marginal zone composed of cells immunopositive to reelin and calretinin, two markers of the glutamatergic Cajal-Retzius cells. Antibodies against $\beta$ III-tubulin stain cells in the marginal zone, in the superficial migratory stream, and the hippocampal plate. Antibodies against vGlut3 reveal the presence of an intense immunostaining of the hippocampal intermediate zone, plate, and subplate. However, these antibodies do not stain any GAD67-EGFP-positive cell. Therefore, GFP cells intermingle with cells immunopositive to $\beta$ III-tubulin and to vGlut3 within the hippocampal plate-subplate. hiz, Hippocampal intermediate zone; hp, hippocampal plate; mz, marginal zone; sms, superficial migratory stream; Sub, subiculum; svz, subventricular zone; vz, ventricular zone. Scale bars: $\boldsymbol{A}, \boldsymbol{D}, \boldsymbol{F}, \boldsymbol{H}, \boldsymbol{J}, 100 \mu \mathrm{m} ; \boldsymbol{B}, \boldsymbol{C}, \boldsymbol{E}, \boldsymbol{G}, \boldsymbol{I}, \boldsymbol{K}$ $20 \mu \mathrm{m}$.

primordium, an important amount of $\beta$ III-tubulin-positive neurons were already present at the level of hippocampal plate of the presumptive CA1 and CA3 fields (Fig. $3 F, G$ ). These neurons were immunonegative for GAD67 (Fig. $3 F, G$ ) and GABA (data not illustrated). Furthermore, these cells were immunopositive for the vesicular glutamate transporter vGlut3 (Fig. $3 H, I$ ), strongly suggesting that these neurons were glutamatergic pioneer neurons, generated before E15; these cells are likely to be pioneer pyramidal cells that were generated in mice by E14 or earlier (Manent et al., 2005, their supplemental data). No staining was observed with vGlut1 or vGlut2 antibodies (data not shown).

Thus, pioneer tangentially migrating interneurons on their long journey to the hippocampal primordium mainly navigate along a superficial migratory stream, lining the marginal zone containing Cajal-Retzius cells. Once they reach the hippocampal primordium, migrating interneurons change direction to invade the developing hippocampal plate, composed of pioneer pyramidal neurons. These migratory pathways correspond to glutamate-enriched areas: (1) glutamatergic Cajal-Retzius cells of

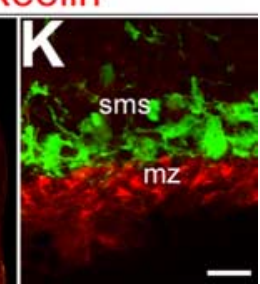

the marginal zone (del Rio et al., 1995; Hevner et al., 2003) and (2) pioneer glutamatergic neurons of the developing CA fields. We hypothesized that this "glutamatergic environment" is required for an appropriate interneuronal migration. In addition, GABA released from GABAergic migrating neurons might contribute to their migration in an "autocrine-paracrine" manner, as shown previously in the rostral migratory pathway (Bolteus and Bordey, 2004).

\section{Glutamate acting through AMPA, but not NMDA, receptors modulates the migration of \\ GAD67-EGFP interneurons}

To investigate whether transmitters, and in particular glutamate, play a role on interneuronal migration, E15 organotypic slices from GAD67-EGFP KI embryos were maintained for 3 DIV in the presence of antagonists for GABA and glutamate receptors. GAD67-EGFP interneurons in organotypic slice cultures were allowed to migrate to the hippocampal primordium in a culture medium supplemented with pharmacological agents. Time-lapse analyses were performed to evaluate the migration of GFP cells, and quantifications were performed daily from 1 to 3 DIV on reconstructed slices (Fig. 4).

In the absence of any pharmacological treatment, the density of GAD67-EGFP migrated interneurons was gradually increased at the level of the hippocampal primordium (from $0.16 \pm 0.16$ cells per surface unit at $1 \mathrm{DIV}$ to $0.64 \pm 0.39$ at 2 DIV and $1.03 \pm 0.55$ at $3 \mathrm{DIV} ; n=9$ experiments, 1267 cells) (Fig. $4 \mathrm{~B}$ ), indicating that neuronal migration occurred and was robust in organotypic slice cultures. In addition, short time-lapse imaging on cultivated slices taken after 1 DIV revealed the presence of GAD67-EGFP interneurons eliciting leading process elongation and somal translocation, two typical features of migrating interneurons (Fig. 2D).

When GAD67-EGFP interneurons were allowed to migrate in the presence of $30 \mu \mathrm{M} \mathrm{CNQX}$, an antagonist of the AMPA/KA receptors, the time-dependent increase in cell density at the level of the hippocampal primordium was importantly modified compared with the control condition: at $3 \mathrm{DIV}$, the density of migrated interneurons in the hippocampal primordium was reduced from $1.03 \pm 0.55$ cells per surface unit in the control condition to $0.34 \pm 0.21$ cells per surface unit after CNQX $(p<$ $0.01 ; n=6$ experiments, 301 cells) (Fig. $4 B, C$ ). Similar results were obtained after 3 DIV in the presence of $10 \mu \mathrm{M}$ NBQX, an antagonist of AMPA receptors $(0.45 \pm 0.23$ cells per surface unit; $p<0.05 ; n=6$ experiments, 396 cells) (Fig. $4 C$ ).

The density of migrated interneurons in the hippocampal primordium was not significantly decreased after 3 DIV in the presence of the $\mathrm{GABA}_{\mathrm{A}}$ receptors antagonists bicuculline $(50 \mu \mathrm{M})$ or gabazine $(10 \mu \mathrm{M})$ compared with the control condition $(0.61 \pm$ 
0.43 cells per surface unit after bicuculline, $n=6$ experiments, 491 cells; $0.59 \pm 0.29$ cells per surface unit after gabazine, $n=6$ experiments, 529 cells) (Fig. $4 B, C$ ). The density of migrated interneurons in the hippocampal primordium was also not significantly decreased after 3 DIV in the presence of the NMDA receptors antagonists MK801 $(10 \mu \mathrm{M})$ and D-APV $(80 \mu \mathrm{M})$ compared with the control condition $(0.69 \pm 0.46$ cells per surface unit after MK801, $n=6$ experiments, 671 cells; $0.62 \pm 0.49$ cells per surface unit after D-APV, $n=6$ experiments, 454 cells) (Fig. $4 B, C)$.

Furthermore, the overall distribution of migrated interneurons within the hippocampal primordium was not significantly modified after $\mathrm{GABA}_{\mathrm{A}}$ or NMDA receptor antagonist treatment compared with the control condition (data not illustrated).

Importantly, pharmacological treatments influenced neither cell proliferation nor cell survival, because the density of $\mathrm{BrdU}^{+}$cells at the level of the ganglionic eminences, as well as the number of propidium iodide-positive cells in the hippocampal primordium were not significantly different from the control condition (supplemental data and Fig. S1, available at www.jneurosci.org as supplemental material).

Thus, antagonizing the effects of glutamate acting through AMPA receptors impaired interneuronal migration in organotypic slice cultures from GAD67-EGFP $\mathrm{KI}$ embryos. In contrast, antagonizing the effects of glutamate acting through NMDA receptors or the effects of GABA acting through $\mathrm{GABA}_{\mathrm{A}}$ receptors did not significantly impair migration. These results suggest that only glutamate acting through AMPA receptors play a role in the modulation of interneuronal migration.

\section{Tangentially migrating GAD67-EGFP interneurons express} AMPA, NMDA, and $\mathrm{GABA}_{\mathrm{A}}$ receptors

To analyze whether the absence of any migration defects during NMDA or $\mathrm{GABA}_{\mathrm{A}}$ receptor antagonist treatment was attributable to an absence of expression of these receptors by migrating interneurons, we performed immunohistological analyzes on hippocampal sections from E15 GAD67-EGFP KI embryos. As reported previously by Metin et al. (2000), for migrating interneurons of the neocortical intermediate zone, GAD67-EGFP interneurons migrating to the hippocampal primordium express the GluR1 subunit of the AMPA receptors (Fig. 5A,B). The GluR1 immunoreactivity was strictly restricted to the superficial interneuronal migration pathway (Fig. $5 A$ ), virtually decorating only tangentially migrating interneurons (Fig. $5 A, B$ ). Tangentially migrating interneurons were also immunoreactive for the $\mathrm{GABA}_{\mathrm{A}}$ receptors (Fig. $5 C$ ) and the NR1 and NR2A/B subunits of the NMDA receptors (Fig. $5 D, E$ ). NR1 staining was rather ubiquitous and concerned GAD67-EGFP-positive and negative cells,
A2 Migrated cells in the hippocampal primordium at 3DIV
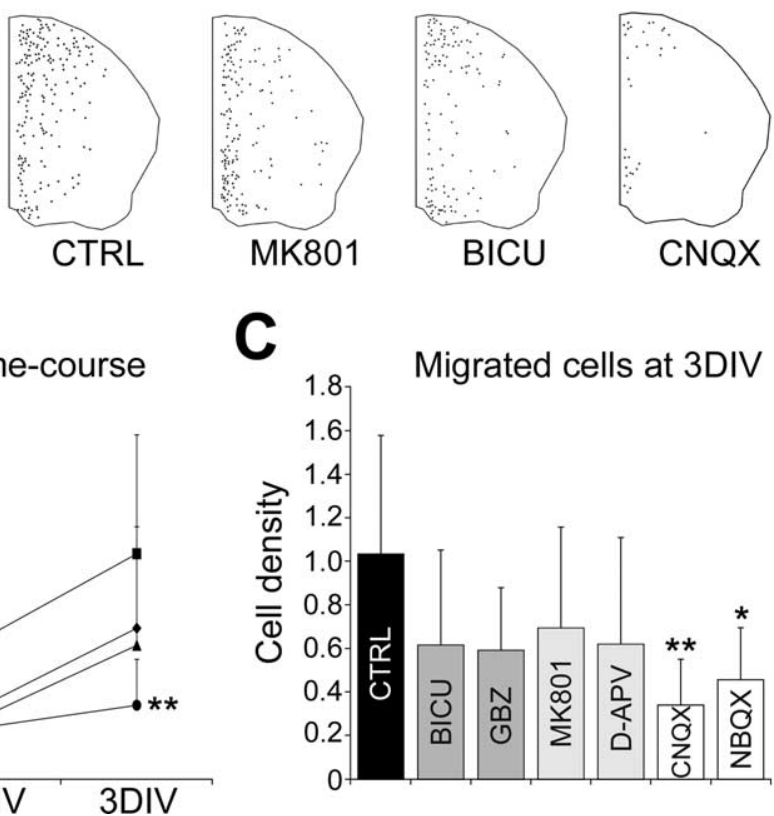

Migrated cells at 3DIV

Figure 4. $\quad$ AMPA receptor antagonists, but not $G_{A B A}$ or NMDA receptor antagonists, perturb the migration of GAD67-EGFP interneurons to the hippocampal primordium. A1, Reconstruction of an organotypic explant from E15 GAD67-EGFP KI mice after The preparation includes the ganglionic eminences, the neocortex, and the hippocampal primordium (square, show (1) Reconstructions of hippocampal primordia from E15 GAD67-EGFP KI mice cultured for 3 DIV without an . . Hippocampal sections were cultured for 3 DIV without any treatment [control condition (CTRL)] or in Living slices were imaged daily for cell densities analyses. CHistogram illustrating ( + SD) the density of GAD67-EGFP migrated (cells per surface unit, arbitrary set to $3600 \mu \mathrm{m}^{2}$ ) in the hippocampal primordium after 3 DIV without any treatment [contro MK801 or 80 ( cell migration. Mann-Whitney U test, ${ }^{*} p<0.05,{ }^{* *} p<0.01$ compared with the control. hip-pr, Hippocampal primordium; LGE, lateral ganglionic eminence; MGE, medial ganglionic eminence; $N C x$, neocortex.

whereas NR2A/B staining was more restricted to GAD67-EGFP neurons. Because NR2A mRNA only became detectable after birth (Monyer et al., 1994), this latter immunostaining likely represented NR2B subunit expression.

Therefore, the lack of effect of $\mathrm{GABA}_{\mathrm{A}}$ and NMDA receptor blockade on the tangential migration of interneurons is not attributable to an absence of NMDA or $\mathrm{GABA}_{\mathrm{A}}$ receptors.

\section{Discussion}

In the present study, we report that GABAergic interneurons colonize the hippocampus mainly via a superficial pathway paved with pioneer glutamatergic neurons. We show that AMPA receptor blockade impairs hippocampal interneuronal migration, whereas NMDA and $\mathrm{GABA}_{\mathrm{A}}$ receptor blockade fail to induce any major change. These data contrast with our previous report (Manent et al., 2005) demonstrating that hippocampal pyramidal cell migration is modulated by mainly $\mathrm{GABA}_{\mathrm{A}}$ and, to a lesser degree, NMDA receptors, but not AMPA. We propose the following: (1) the migration of distinct neuronal subtypes, using specific modes of migration and migratory pathways, is modulated through different mechanisms; and (2) glutamatergic and GABAergic neurons modulate their migration in a synergistic and cooperative 

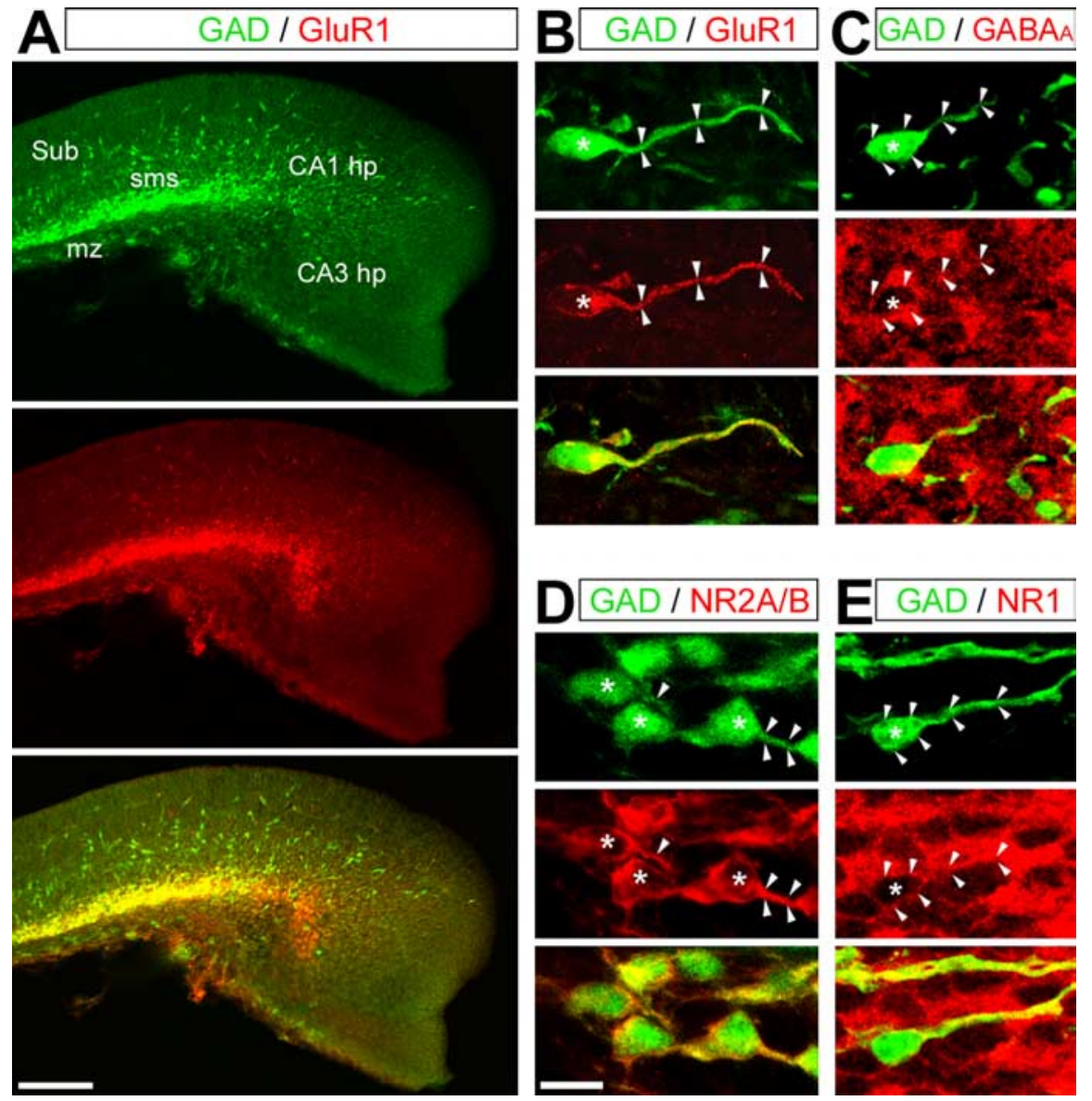

Figure 5. GAD67-EGFP interneurons express AMPA, NMDA, and GABA, receptors. Confocal photomicrographs (z-projections) of E15 hippocampal sections double labeled with antibodies against GFP (green) and against different receptor subunits (red). Merged images are presented in the bottom panels. The asterisks indicate cell nuclei, and the arrowheads delineate somata and leading processes. $\boldsymbol{A}, \boldsymbol{B}$, Immunostaining for GFP and the GluR1 subunit of the AMPA receptor. Note that the GluR1 staining is strictly restricted to GAD67-EGFP migrating interneurons, decorating the somata and the leading processes. $\boldsymbol{C}$, Immunostaining for GFP and the $\beta$-chain of the $G_{A B A_{A}}$ receptor. $\mathrm{GABA}_{\mathrm{A}}$ receptor staining is relatively ubiquitous and present at the somata and leading processes of GAD67-EGFP migrating interneurons. $\boldsymbol{D}, \boldsymbol{E}$, Immunostaining for GFP and the NR2A/B $(\boldsymbol{D})$ and NR1 (E) subunits of the NMDA receptor. NR1 staining is rather ubiquitous and concerns GFP-positive and GFP-negative cells, whereas NR2A/B staining is more restricted to GAD67-EGFP neurons. Both stainings decorate the somata and leading processes of migrating interneurons. hp, Hippocampal plate; mz, marginal zone; sms, superficial migratory stream; Sub, subiculum. Scale bars: $\boldsymbol{A}$, 100 $\mu \mathrm{m} ; \boldsymbol{B}-\boldsymbol{E}, 20 \mu \mathrm{m}$.

manner, constituting one of the first homeostatic mechanisms operating in the developing brain.

Transmitters as developmental signals: diverse modulations and diverse modes of neuronal migration

In this report, tangential migration of interneurons in organotypic explants from GAD67-EGFP KI mice is reduced by AMPA but not NMDA or $\mathrm{GABA}_{\mathrm{A}}$ receptor blockade. Interestingly, $\mathrm{Me}$ tin et al. (2000) have shown that AMPA receptors expressed by migrating interneurons in the neocortical IZ are highly permeable to calcium, because they apparently fail to express the GluR2 subunit. The activation of these calcium-permeable AMPA receptors might induce modifications in the intracellular calcium levels via a direct calcium influx through these channels and indirectly through the depolarization-mediated activation of voltage-dependent calcium channels. Therefore, the release of glutamate from adjacent Cajal-Retzius cells or pioneer pyramidal neurons would generate calcium signals. These intracellular calcium transients would result in the modification of cell motility, because changes in their frequencies have been shown to affect
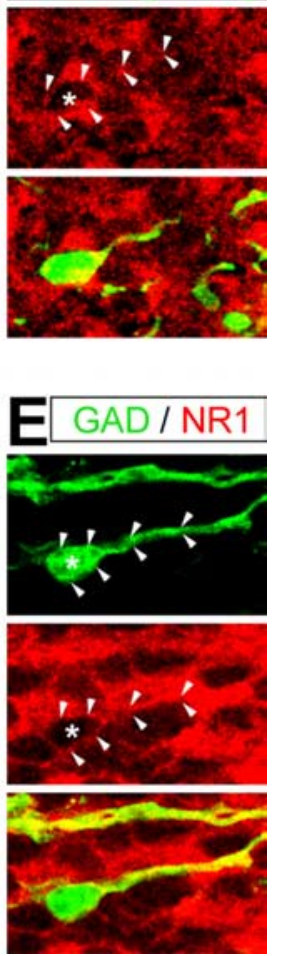

the rate of migration of cerebellar granule cells (for review, see Komuro and $\mathrm{Ku}-$ mada, 2005). However, it is more difficult to explain the absence of effects of $\mathrm{GABA}_{\mathrm{A}}$ and NMDA receptors blockade because migrating interneurons express $\mathrm{GABA}_{\mathrm{A}}$ and NMDA receptors (Soria and Valdeolmillos, 2002). Interestingly, patch-clamp analysis clearly shows that migrating interneurons of the neocortical IZ do not respond to NMDA application (Metin et al., 2000). In addition, currents evoked by $\mathrm{GABA}_{\mathrm{A}}$ receptor agonists (GABA and isoguvacine) induced rapidly desensitizing responses of small amplitude in these neurons. These data suggest that both NMDA and $\mathrm{GABA}_{\mathrm{A}}$ receptors would not be major contributors to calcium transients in migrating interneurons.

In contrast, the radial migration of hippocampal pyramidal cells is strongly modulated by $\mathrm{GABA}_{\mathrm{A}}$ and NMDA but not AMPA receptors (Behar et al., 1998, 1999, 2000; Hirai et al., 1999; Kihara et al., 2002; Manent et al., 2005). The lack of effect of AMPA receptor antagonists is attributable to the absence of operative AMPA receptors on migrating pyramidal cells (Manent et al., 2005), at least in the hippocampus. Thus, a major difference in the calcium signals is expected between pyramidal neurons and interneurons: the former operate by means of the $\mathrm{GABA}_{\mathrm{A}} / \mathrm{NMDA}$ synergy with the excitatory actions of GABA removing the voltage-dependent blockade of NMDA channels (Leinekugel et al., 1995). In contrast, in interneurons, this synergistic action is not operative; calcium signals would be generated via the direct depolarization through the activation of AMPA receptors by the released glutamate that directly triggers a calcium influx.

Data on the effects of transmitters on cell migration indicated contrasting effects depending on distinct neuronal subtypes. Thus, interneurons migrating from the anterior SVZ to the olfactory bulb display a characteristic "saltatory" mode of migration (Wichterle et al., 1997) mainly modulated by GABA (Bolteus and Bordey, 2004). These authors, however, proved that, in these neurons, $\mathrm{GABA}_{\mathrm{A}}$ receptor activation rather reduces the migration rate, whereas the blockade of these receptors with bicuculline enhances the migration rate, thus showing an opposite effect compared with radially migrating pyramidal cells in hippocampal explants (Manent et al., 2005). Interestingly, olfactory bulb interneurons express $\mathrm{GABA}_{\mathrm{A}}$ and then AMPA receptors but not NMDA receptors while migrating tangentially (Carleton et al., 2003); the expression of functional NMDA receptors was observed only when the cells reached the olfactory bulb and changed their mode of migration to a radial migration. It is thus plausible that tangential migration in the rostral migratory stream is modulated by $\mathrm{GABA}_{\mathrm{A}}$ and then eventually AMPA, whereas the radial migration in the olfactory bulb would be mediated by NMDA. These differences strongly suggest that the modulation of neuronal migration is time, stage, and population dependent. 


\section{Glutamatergic and GABAergic hippocampal neurons modulate their migration in a synergistic and cooperative manner: a hypothetical model for the orchestration of hippocampal construction}

In adult networks, the equilibrium between the activity of GABAergic and glutamatergic neurons is essential for the generation of behavioral relevant patterns. Our present data strongly suggest that this coordination most likely starts at a very early stage. We propose as a working hypothesis that glutamatergic neurons modulate the migration of GABAergic interneurons (this report) and that GABA neurons modulate the migration of glutamatergic pyramidal cells (supplemental Fig. S2, available at www.jneurosci.org as supplemental material) (Behar et al., 1998, 2000; Manent et al., 2005).

Pioneer Cajal-Retzius cells (del Rio et al., 1995; Hevner et al., 2003) and glutamatergic pyramidal cells, which proliferate in the hippocampus from E12 [Manent et al. (2005), their supplemental data], provide an early source of glutamate in the hippocampal primordium. In addition, glial cells (by this period of life, radial glial cells) might also release glutamate (Angulo et al., 2004). The expression of functional glutamate transporters in embryonic hippocampus (Demarque et al., 2002) limits, however, the action of glutamate, and a close contact between migrating interneurons and glutamate-releasing cells is required (Metin et al., 2000). Tangentially migrating interneurons within the hippocampus follow a superficial pathway in close contact with vGlut3immunopositive cells in the hippocampal plate and adjacent to the marginal zone, enriched in Cajal-Retzius cells. Migrating interneurons in the superficial migratory stream are in contrast far away from radial glia cell bodies (vimentin- and nestinimmunoreactive cells were rather localized in the ventricularsubventricular zone) and did not follow radial glial extensions. Radial glial cells might in contrast play a more pronounced role for radial migration, when interneurons leave their main migratory stream to follow radial glial extensions.

The unique source of GABA in the hippocampal primordium is the GABAergic migrating interneurons, because GABA antibodies stained only GAD67-EGFP cells in hippocampal sections. The effects of ambient GABA are likely to be facilitated by a weak clearance from the extracellular space attributable to a poor functional maturation of GABA transporters, at least of the main hippocampal GABA transporter GAT1 (Demarque et al., 2002). Accordingly to this, GABA might easily diffuse in the hippocampal complex and activate relatively distant cells. This would explain that GABA is able to modulate pyramidal cell migration from the subventricular zone, in which they are generated, to the hippocampal plate. The effects of GABA on $\mathrm{GABA}_{\mathrm{A}}$ receptors expressed by migrating pyramidal cells would be reinforced by the action of glutamate on NMDA receptors, via a coordinated cooperation between these two receptor types as that reported previously in neonatal hippocampal slices (Leinekugel et al., 1997). Thus, glutamate released from pioneer glutamatergic neurons would facilitate the migration of GABAergic interneurons, which in turn would release GABA, facilitating the migration of glutamatergic neuroblasts (supplemental Fig. S2, available at www.jneurosci.org as supplemental material). These cooperative effects would contribute to construct a balanced system in terms of time of arrival of new neurons and relative numbers of each neuronal subtypes, thus avoiding the requirement of a massive elimination of exceeding migrated cells. This notion also implies that perturbing one of the two neuronal subtypes during brain maturation would consequently result in an alteration of the second one. Interestingly, cortical heterotopias generated in rats ex- posed to methylazoxymethanol in utero (Chevassus-Au-Louis et al., 1998) or by RNA interference knockdown of doublecortin (Ramos et al., 2006) not only contain cortical pyramidal cells but GABAergic interneurons as well. Thus, heterotopias, constituted originally of pyramidal cells that failed to migrate radially to the cortical plate, also attract and retain migrating interneurons. Although speculative, it is tempting to suggest that the reciprocal interactions between glutamatergic and GABAergic systems are contributing with other factors to this cell population-dependent defect.

\section{References}

Anderson SA, Eisenstat DD, Shi L, Rubenstein JL (1997) Interneuron migration from basal forebrain to neocortex: dependence on Dlx genes. Science 278:474-476.

Anderson SA, Marin O, Horn C, Jennings K, Rubenstein JL (2001) Distinct cortical migrations from the medial and lateral ganglionic eminences. Development 128:353-363.

Ang Jr ES, Haydar TF, Gluncic V, Rakic P (2003) Four-dimensional migratory coordinates of GABAergic interneurons in the developing mouse cortex. J Neurosci 23:5805-5815.

Angulo MC, Kozlov AS, Charpak S, Audinat E (2004) Glutamate released from glial cells synchronizes neuronal activity in the hippocampus. J Neurosci 24:6920-6927.

Bayer SA (1980) Development of the hippocampal region in the rat. I. Neurogenesis examined with ${ }^{3} \mathrm{H}$-thymidine autoradiography. J Comp Neurol 190:87-114.

Behar TN, Schaffner AE, Scott CA, O’Connell C, Barker JL (1998) Differential response of cortical plate and ventricular zone cells to GABA as a migration stimulus. J Neurosci 18:6378-6387.

Behar TN, Scott CA, Greene CL, Wen X, Smith SV, Maric D, Liu QY, Colton CA, Barker JL (1999) Glutamate acting at NMDA receptors stimulates embryonic cortical neuronal migration. J Neurosci 19:4449-4461.

Behar TN, Schaffner AE, Scott CA, Greene CL, Barker JL (2000) GABA receptor antagonists modulate postmitotic cell migration in slice cultures of embryonic rat cortex. Cereb Cortex 10:899-909.

Bolteus AJ, Bordey A (2004) GABA release and uptake regulate neuronal precursor migration in the postnatal subventricular zone. J Neurosci 24:7623-7631.

Carleton A, Petreanu LT, Lansford R, Alvarez-Buylla A, Lledo PM (2003) Becoming a new neuron in the adult olfactory bulb. Nat Neurosci 6:507-518.

Chevassus-Au-Louis N, Rafiki A, Jorquera I, Ben Ari Y, Represa A (1998) Neocortex in the hippocampus: an anatomical and functional study of CA1 heterotopias after prenatal treatment with methylazoxymethanol in rats. J Comp Neurol 394:520-536.

de Carlos JA, Lopez-Mascaraque L, Valverde F (1996) Dynamics of cell migration from the lateral ganglionic eminence in the rat. J Neurosci 16:6146-6156.

del Rio JA, Martinez A, Fonseca M, Auladell C, Soriano E (1995) Glutamatelike immunoreactivity and fate of Cajal-Retzius cells in the murine cortex as identified with calretinin antibody. Cereb Cortex 5:13-21.

Demarque M, Represa A, Becq H, Khalilov I, Ben Ari Y, Aniksztejn L (2002) Paracrine intercellular communication by a $\mathrm{Ca}^{2+}$ - and SNAREindependent release of GABA and glutamate prior to synapse formation. Neuron 36:1051-1061.

Gras C, Vinatier J, Amilhon B, Guerci A, Christov C, Ravassard P, Giros B, El Mestikawy S (2005) Developmentally regulated expression of VGLUT3 during early post-natal life. Neuropharmacology 49:901-911.

Hevner RF, Neogi T, Englund C, Daza RA, Fink A (2003) Cajal-Retzius cells in the mouse: transcription factors, neurotransmitters, and birthdays suggest a pallial origin. Brain Res Dev Brain Res 141:39-53.

Hirai K, Yoshioka H, Kihara M, Hasegawa K, Sakamoto T, Sawada T, Fushiki S (1999) Inhibiting neuronal migration by blocking NMDA receptors in the embryonic rat cerebral cortex: a tissue culture study. Brain Res Dev Brain Res 114:63-67.

Jimenez D, Lopez-Mascaraque LM, Valverde F, de Carlos JA (2002) Tangential migration in neocortical development. Dev Biol 244:155-169.

Kihara M, Yoshioka H, Hirai K, Hasegawa K, Kizaki Z, Sawada T (2002) Stimulation of $N$-methyl-D-aspartate (NMDA) receptors inhibits neuro- 
nal migration in embryonic cerebral cortex: a tissue culture study. Brain Res Dev Brain Res 138:195-198.

Komuro H, Kumada T (2005) $\mathrm{Ca}^{2+}$ transients control CNS neuronal migration. Cell Calcium 37:387-393.

Komuro H, Rakic P (1993) Modulation of neuronal migration by NMDA receptors. Science 260:95-97.

Komuro H, Rakic P (1998) Orchestration of neuronal migration by activity of ion channels, neurotransmitter receptors, and intracellular $\mathrm{Ca}^{2+}$ fluctuations. J Neurobiol 37:110-130.

Kriegstein AR, Noctor SC (2004) Patterns of neuronal migration in the embryonic cortex. Trends Neurosci 27:392-399.

Lavdas AA, Grigoriou M, Pachnis V, Parnavelas JG (1999) The medial ganglionic eminence gives rise to a population of early neurons in the developing cerebral cortex. J Neurosci 19:7881-7888.

Leinekugel X, Tseeb V, Ben Ari Y, Bregestovski P (1995) Synaptic GABAA activation induces $\mathrm{Ca}^{2+}$ rise in pyramidal cells and interneurons from rat neonatal hippocampal slices. J Physiol (Lond) 487: 319-329.

Leinekugel X, Medina I, Khalilov I, Ben Ari Y, Khazipov R (1997) $\mathrm{Ca}^{2+}$ oscillations mediated by the synergistic excitatory actions of GABA(A) and NMDA receptors in the neonatal hippocampus. Neuron 18:243-255.

Lopez-Bendito G, Lujan R, Shigemoto R, Ganter P, Paulsen O, Molnar Z (2003) Blockade of GABA(B) receptors alters the tangential migration of cortical neurons. Cereb Cortex 13:932-942.

Manent JB, Demarque M, Jorquera I, Pellegrino C, Ben Ari Y, Aniksztejn L, Represa A (2005) A noncanonical release of GABA and glutamate modulates neuronal migration. J Neurosci 25:4755-4765.

Marin O, Rubenstein JL (2003) Cell migration in the forebrain. Annu Rev Neurosci 26:441-483.

Metin C, Denizot JP, Ropert N (2000) Intermediate zone cells express calcium-permeable AMPA receptors and establish close contact with growing axons. J Neurosci 20:696-708.

Monyer H, Burnashev N, Laurie DJ, Sakmann B, Seeburg PH (1994) Developmental and regional expression in the rat brain and functional properties of four NMDA receptors. Neuron 12:529-540.

Nadarajah B, Parnavelas JG (2002) Modes of neuronal migration in the developing cerebral cortex. Nat Rev Neurosci 3:423-432.

Nadarajah B, Alifragis P, Wong RO, Parnavelas JG (2002) Ventricledirected migration in the developing cerebral cortex. Nat Neurosci 5:218-224.

Nery S, Fishell G, Corbin JG (2002) The caudal ganglionic eminence is a source of distinct cortical and subcortical cell populations. Nat Neurosci 5:1279-1287.

Pleasure SJ, Anderson S, Hevner R, Bagri A, Marin O, Lowenstein DH,
Rubenstein JL (2000) Cell migration from the ganglionic eminences is required for the development of hippocampal GABAergic interneurons. Neuron 28:727-740.

Polleux F, Whitford KL, Dijkhuizen PA, Vitalis T, Ghosh A (2002) Control of cortical interneuron migration by neurotrophins and PI3-kinase signaling. Development 129:3147-3160.

Poluch S, Konig N (2002) AMPA receptor activation induces GABA release from neurons migrating tangentially in the intermediate zone of embryonic rat neocortex. Eur J Neurosci 16:350-354.

Poluch S, Drian MJ, Durand M, Astier C, Benyamin Y, Konig N (2001) AMPA receptor activation leads to neurite retraction in tangentially migrating neurons in the intermediate zone of the embryonic rat neocortex. J Neurosci Res 63:35-44

Ramos RL, Bai J, LoTurco JJ (2006) Heterotopia formation in rat but not mouse neocortex after RNA interference knockdown of DCX. Cereb Cortex, in press.

Soria JM, Valdeolmillos M (2002) Receptor-activated calcium signals in tangentially migrating cortical cells. Cereb Cortex 12:831-839.

Soriano E, Cobas A, Fairen A (1989) Neurogenesis of glutamic acid decarboxylase immunoreactive cells in the hippocampus of the mouse. I. Regio superior and regio inferior. J Comp Neurol 281:586-602.

Stanfield BB, Cowan WM (1979) The development of the hippocampus and dentate gyrus in normal and reeler mice. J Comp Neurol 185:423-459.

Stoppini L, Buchs PA, Muller D (1991) A simple method for organotypic cultures of nervous tissue. J Neurosci Methods 37:173-182.

Tamamaki N, Yanagawa Y, Tomioka R, Miyazaki J, Obata K, Kaneko T (2003) Green fluorescent protein expression and colocalization with calretinin, parvalbumin, and somatostatin in the GAD67-GFP knock-in mouse. J Comp Neurol 467:60-79.

Tanaka D, Nakaya Y, Yanagawa Y, Obata K, Murakami F (2003) Multimodal tangential migration of neocortical GABAergic neurons independent of GPI-anchored proteins. Development 130:5803-5813.

Wichterle H, Garcia-Verdugo JM, Alvarez-Buylla A (1997) Direct evidence for homotypic, glia-independent neuronal migration. Neuron 18:779-791.

Wichterle H, Turnbull DH, Nery S, Fishell G, Alvarez-Buylla A (2001) In utero fate mapping reveals distinct migratory pathways and fates of neurons born in the mammalian basal forebrain. Development 128:3759-3771.

Yozu M, Tabata H, Nakajima K (2005) The caudal migratory stream: a novel migratory stream of interneurons derived from the caudal ganglionic eminence in the developing mouse forebrain. J Neurosci 25:72687277. 